\title{
Las Llaves de la Ciudad. Mecanismos para Propiciar el Cambio Social
}

\author{
The Key to the City. Mechanisms to Promote Social Change
}

\section{A Chave para a Cidade. Mecanismos para Promover a Mudança Social}

\author{
Carlos Arruti * \\ Anabel Varona
}

Maushaus, Taller de Arquitectura

\begin{abstract}
La participación infantil en los procesos del diseño del medio ambiente construido, promete ser ya, uno de los retos y uno de los mayores agentes transformadores de los conceptos que actualmente rigen la planificación urbana. Mostramos a lo largo de este artículo cómo trabajar con la estructura de la realidad que nos circunda, para conocerla, comprenderla y aprender a jugar con su complejidad desde edades tempranas. Planteamos cómo operar hacia la recuperación lógica urbana, asegurando la interlocución y la participación de los estudiantes en las decisiones democráticas. Mostraremos también los resultados, que apuntan hacia una urbanidad más deseable para las personas y unos modelos de ciudad más lógicos y sostenibles que los actuales.
\end{abstract}

Descriptores: Infancia, Creación artística, Planificación urbana, Cambio social, Lógica.

The participation of children in the processes of designing the built environment, promises to be already one of the challenges and one of the major transforming agents of the concepts that currently govern urban planning. We show throughout this article how to work with the structure of the reality that surrounds us, to know it, to understand it and to learn to play with its complexity from an early age. We propose how to operate towards urban logical recovery, ensuring dialogue and student participation in democratic decisions. We will also show results, that point to a more desirable urbanity for people and more logical and sustainable city models than the current ones.

Keywords: Childhood, Artistic creation, Urban planning, Social change, Logic.

A participação das crianças nos processos de desenho do ambiente construído promete ser um dos desafios e um dos maiores agentes de mudança nos conceitos que regem o planeamento urbano. Ao longo deste artigo mostramos como trabalhar com a estrutura da realidade que nos rodeia, para conhecê-la, compreendê-la e aprender a jogar com a sua complexidade desde a jovem idade. Propomos como actuar para uma recuperação lógica urbana, assegurando o diálogo e a participação dos alunos nas decisões democráticas. Também mostramos os resultados, apontando para uma urbanidade mais desejável para as pessoas e para modelos de cidade mais lógicos e sustentáveis dos atuais.

Palavras-chave: Infância, Criação artística, Planeamento urbano, Mudança social, Lógica.

*Contacto: carlos@maushaus.info

ISSN: 2254-3139

www.rinace.net/riejs/

revistas.uam.es/riejs
Recibido: $\quad 5$ de diciembre 2016

$1^{\text {a }}$ Evaluación: 4 de enero 2017

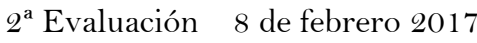

Aceptado: $\quad 5$ de marzo 2017 
Conscientes del amplio espectro de experiencias internacionales en torno a la educación infantil en arte y arquitectura, actualmente es extremadamente difícil aproximar una visión panorámica de lo que es, o de lo que debería ser. Sí que podremos decir, que la motivación que nos ha llevado a nosotros y quizás a otros colectivos que trabajan en este campo, a cooperar activamente con la infancia dentro y fuera del marco de la educación reglada para conocer los mecanismos de la planificación urbana y su lógica, está relacionada con la sensación de responsabilidad en la transmisión patrimonial de nuestras ciudades y territorios a las generaciones venideras. Queremos enseñarles mucho y bien, para que dispongan de autonomía en sus decisiones de la vida adulta y sean libres en sus ciudades.

$\mathrm{Si}$ nos remontamos al origen de las polis griegas, donde fundaban las ciudades sobre sólidos cimientos de roca y elaboraban la construcción de la justicia como la más completa de las virtudes humanas para el manejo y conservación del mundo, veríamos que a la par que esculpían con precisión la piedra, trataban también de afianzar la construcción moral y política de sus habitantes libres, tallando a estos en la equidad y la igualdad. Sin embargo, si fuese posible trasladarse a ese tiempo, veríamos asomarse en las primeras democracias, las fisuras tras la puesta en marcha de una sociedad perfectamente utópica. Las cartas de Platón a la muerte de Sócrates (Platón, trad. en 2010) o las intrigas populistas de Pericles (Tucídides, trad. en 2004), ponen sin duda en evidencia la imprevisibilidad y la dificultad intrínsecas de gestionar la polis de manera justa.

Esto no quiere decir que nosotros al seguir ese modelo, hayamos heredado con las ciudades y sus leyes, un juguete roto, sino que más bien pone el foco en saber encontrar la belleza dentro la imperfección de los sistemas. Para avanzar hacia sociedades más justas, donde las personas dispongamos de igualdad de oportunidades, en lo cultural, lo social y lo económico, hemos de asumir que los sistemas que se ejercen con la implicación de toda la sociedad, son infinitamente más complejos de gobernar que cuando uno se enfrenta a sí mismo y su propia axiología de valores.

Quizás, podamos vivir desde la esperanza de la capacidad de evolución de las cosas y de las personas, en esa suerte de metamorfosis, que ya enunciaba Lamarck (1971) en su "Filosofía zoológica". Si consideramos el fenómeno urbano como un ser vivo, podremos poner nuestra fe en que si cambiamos los conceptos que codifican a la ciudad, esta adoptará nuevas formas. Reversiblemente, podríamos también pensar que cuando aportemos nuevas formas a la arquitectura de nuestras ciudades, las ideas de las personas, también se transformarán (figura 1).

En materia de desarrollo urbano, más allá de la dimensión económica de nuestras polis modernas y su distribución de riqueza, de las que no trataremos en estas líneas, siempre se generan conflictos e injusticias sociales y siempre existen grupos más vulnerables a padecerlas. Al igual que los colectivos en riesgo de exclusión o las personas con diversidad funcional, la infancia es un sector de la población en constante peligro de discriminación, por su escaso reconocimiento social, a nivel simbólico y sobre todo, por su nula dimensión política, al estar privados de esta representación. Nuestra tarea como educadores también consistirá en estar alerta ante estas cuestiones de falta de representatividad, sabiendo darles voz, e ir de la mano combatiendo conjuntamente las "sin justicias" (Abril, 1918) que se ciernen sobre estos grupos. Deberemos pues, contar con ellos para modelar adecuadamente nuestras calles, para hacerlas más amables y 
cómodas. Luchando virtuosamente contra la injusticia, podremos acabar con la hostilidad e inseguridad urbana hacia la infancia y otros grupos sociales, volviéndose nuestra polis accesible para todos los ciudadanos que la habitan. Pero ¿es posible reconstruir a la lógica urbana?

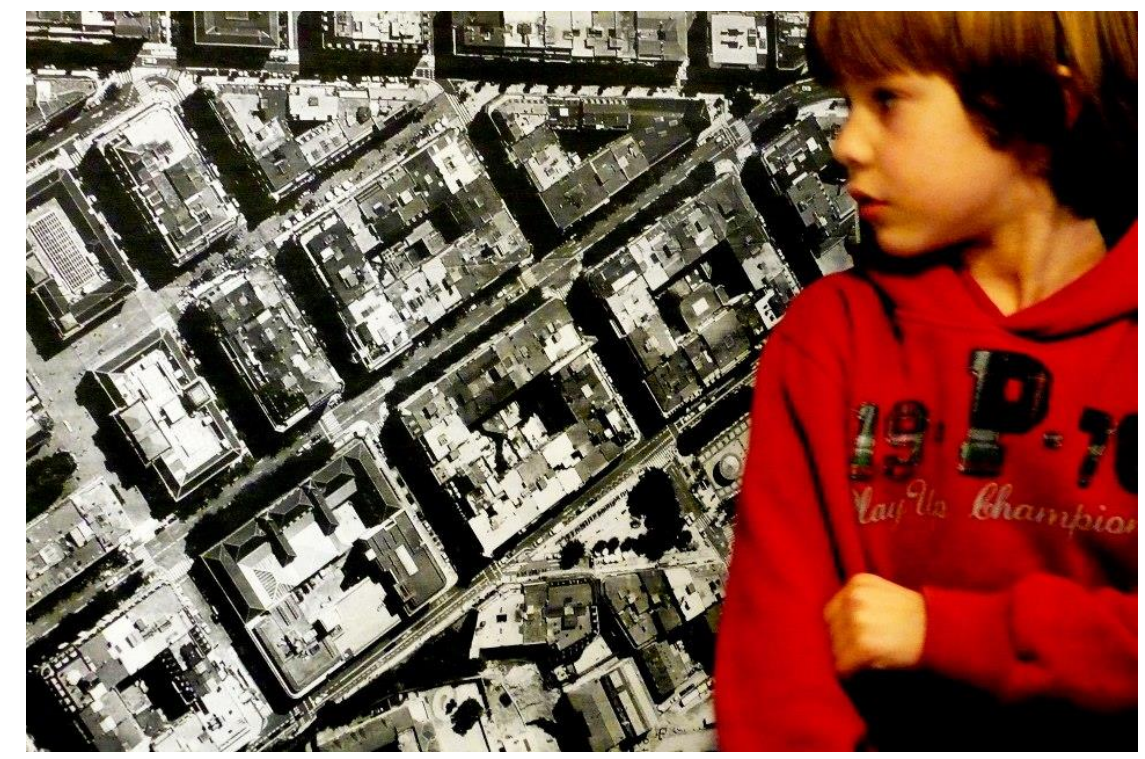

Figura 1. Imagen del proceso San Sebastián ¿Puedes oírnos?

Fuente: Foto de Maushaus 2013.

Saliéndonos nuevamente de la enorme capacidad distorsionadora de la lógica especulativa del medio urbano, y situándonos en el seno del espacio de convivencia, podremos volver al espacio vacío de nuestra ciudad, y percibirlo como la estancia compartida que ha ido adecuando sus formas con la lógica empírica de la experiencia de los habitantes a lo largo de los siglos. Pensemos en la ciudad actual, como esa suma de tantas fuerzas e intereses dispares que la convierten en un potro salvaje que nadie es capaz de dominar. ¿Cómo es un sistema sensible a todas estas fuerzas y a la vez respetuoso con el medio que generosamente la aloja?, ¿Cómo encajan las piezas de la ciudad para readaptarse a la nueva urbanidad?

Más allá de los modelos de participación o de las metodologías de trabajo con las escuelas y que detallaremos en adelante, la cuestión crucial o el leitmotiv que subyace en muchas propuestas educativas, es el miedo generacional. Preferiríamos llamarlo inquietud generacional, pero viendo el desarrollo de nuestro entorno urbano en los últimos veinticinco años, miedo expresa mejor nuestra incertidumbre al futuro cercano de nuestras ciudades y por ende, de nuestras vidas. Las palabras que mejor ilustrarían esto, las escribió Palle Nielsen (2010) en su "Modelo para una sociedad cualitativa", donde expresa el desasosiego que nos produce transmitir un mundo incomprensible a la infancia.

La metáfora de la entrega de llaves de la ciudad a los nuevos ciudadanos, hoy por hoy, casi se torna en parodia, cuando imaginamos a las niñas y niños, introduciendo la llave dorada en los portones de la muralla de seguridad, girando el postigo y apareciendo al otro lado, intramuros, el caos apoderándose de toda una urbe revuelta en un espacio con todo tirado por los suelos, las huchas vacías y las camas por hacer. La visión consciente de la ciudad globalizada, nos genera pequeños cuadros de pánico escénico y mucha 
ansiedad, a la hora de encontrar la lógica y poder transmitírsela a los siguientes usuarios. ¿Cómo nos imaginamos que los más jóvenes hoy harán mejor ciudad que nosotros, con un mal ejemplo? Si conscientemente abandonamos la lógica urbana al capital global, sólo podremos sonrojarnos el día de la entrega de llaves, y sobre todo, no podremos confiar en que los futuros urbanistas abandonen la sinrazón de las lógicas insolidarias que imperan en el corazón de las ciudades (que en nada se parecen a los orígenes de las ciudades que nos hacen agruparnos libremente) y motiven cambios para volver a sociedades más libres.

La manera que se nos ocurre para "reconducir la nave", lo cual se escapa de nuestras posibilidades y pretensiones, es entre otras vías, introducir en las aulas los mismos métodos de creación con los que se genera la ciudad, para que las y los niños en edad escolar, comprendan la gran influencia que tienen las pequeñas decisiones urbanísticas que cada día adoptamos, afectando en su cotidianidad. Afortunadamente las reglas de la ciudad no son rígidas y pueden alterarse. La ciudad en sí misma es un fenómeno mutante y pensamos que no sólo consiste en comunicar a la infancia y juventud los códigos y protocolos que inciden en su espacio vital, sino también transmitirles el espíritu que guía esos códigos de conducta, que velan por su seguridad de acceso de oportunidades a una sociedad igualitaria. Si la equidad y la justicia como modelo, vuelven a "triunfar" en la sociedad, prevaleciendo como principios de interés general, las ciudades del futuro volverán a articular normas y códigos para una sociedad justa.

Pensamos que los centros escolares son idóneos para desarrollar propuestas democráticas, puesto que, en ellos, se produce la mayor representación de la sociedad "en miniatura”, y son lugares en los que la transmisión de información, la toma de decisiones y la gestión continuada de los conflictos, son mucho más ágiles que en otros contextos. Las escuelas son la mejor cuna para la urbanidad, puesto que son las que se encargan de establecer las bases del pensamiento crítico en la sociedad moderna. Durante su etapa escolar los más jóvenes tienen mucho que aprender, pero también mucho que enseñarnos. Como usuarios de la ciudad tienen pleno derecho a comprender los mecanismos que crean su estructura, y a aprender a jugar sanamente en este terreno. Necesitamos su punto de vista diferente del nuestro. Las niñas y los niños, miran a su alrededor llenos de curiosidad, y participan de la vida desde una posición fresca, buscando y alcanzando otras visiones. Sin restarles libertad, podemos ofrecerles el enfoque artístico y cultural del mundo, para ayudarles a desenvolverse de manera sensible en el entorno y a actuar cotidianamente con creatividad. A día de hoy, ya necesitan expresarse, crear y tener un impacto en su propio entorno o en parte de los contextos que les rodean, para comenzar a construir sus propios caminos del mañana (figura 2).

¿Qué nos depara el futuro? ¿Qué forma tiene? Para responder a este tipo de preguntas y muchas más, en el año 2012, creamos junto con el apoyo de "San Sebastián 2016 Capital Europea de la Cultura”, una convocatoria abierta a los centros escolares, para participar en las aulas con una experiencia de urbanismo y formular este tipo de preguntas que revelasen los deseos de las y los más pequeños de la ciudad. El programa se llamó Haurbanistak (juego de palabras entre Haur: niña/o en euskera y Urbanismo). El proyecto, contó en su primera convocatoria con cinco centros. Tras su buena acogida, se organizó una segunda convocatoria en 2013, ampliándose la participación a 12 centros. Durante el curso 2015-16, el proyecto se consolidó y tomó mayor dimensión, llegando a participar hasta 15 centros y más de 1000 escolares, con nuevos contenidos y 
actividades. La suerte de contar con tantos centros, pudo traducirse en un caudal importante de ideas y poder sondear ampliamente el mapa urbano, peri-urbano y rural de la ciudad.

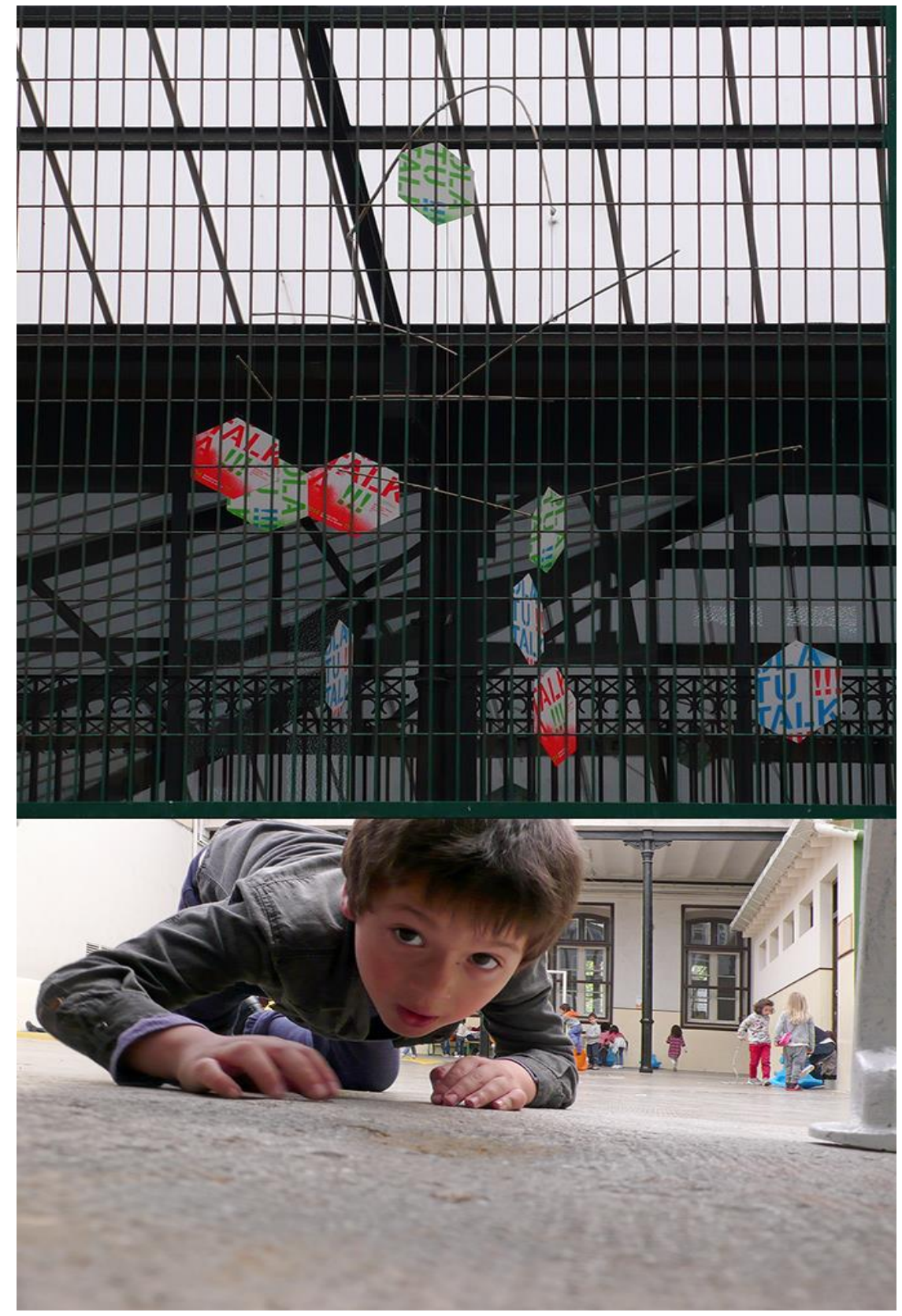

Figura 2. Exposición Haurbanistak 2014

Fuente: Foto Maushaus 2014.

La experiencia se articuló desde sus inicios, a la manera del método científico, por no decir ahora que visto con cierta perspectiva temporal, es un pequeño método abreviado, o un modelo simplificado del MC14 $4^{1}$ aplicado al urbanismo. Ahora bien, la propuesta se

1. Según el Oxford English Dictionary, el método científico es: un método o procedimiento que ha caracterizado a la ciencia natural desde el siglo XVII, que consiste en la observación sistemática, medición, experimentación, la formulación, análisis y modificación de las hipótesis. MC14 es una abreviatura de método científico consistente en 14 etapas. 
apoya en el método, pero sin la pretensión final por obtener una tesis o un modelo final, sino la puesta en común de los participantes del proyecto con la ciudadanía, para evidenciar su punto de vista sobre el medio ambiente construido, de un modo representativo y artístico. Aplicando un método neutral de investigación, se busca lograr la mayor imparcialidad posible en el desarrollo del proyecto, y aprovecharse del rigor que proporciona a los participantes ir progresando, de manera metódica y por etapas, en la investigación de los habitualmente desconocidos entornos urbanos próximos a los centros escolares.

Tras estos años de desarrollo del proyecto, hemos ido incorporando nuevos enfoques que se concretan en tres maneras complementarias de mirar y pensar la ciudad. Tres maneras que nos sirven para diseccionar los problemas y explorar la ciudad desde tres ángulos posibles, que a continuación describimos:

$A$ vista de pájaro. Con la visión conceptual "a vista de pájaro” y extendiendo nuestros sentidos mediante nuestros aeroplanos, satélites, cámaras fotográficas y demás herramientas, humanamente recreamos esas visiones de ave, que en ocasiones solemos llegar a imaginar, cristalizándolas en forma de planos y de bases cartográficas con los que desarrollar el urbanismo moderno. Lo bueno de mirar a vista de pájaro, es que la visión desde el aire, se produce en perpendicular al suelo. Los edificios, sus sombras, la vegetación... nos detallan los volúmenes con precisión y relatan nuestro entorno muy descriptivamente, pero sobre todo, la clave de estas representaciones fotográficas está en que son medibles a escala.

A pie de calle. Figurativamente es la cota de actuación en las calles a la vez que el nivel de contacto con el público y su realidad cotidiana. A pie de calle, la visión es congruente con una mayor multi-sesorialidad, y los estímulos de la percepción aparecen más allá del ojo humano, que en este caso y a pesar de la abundante cultura visual que nos proporciona la ciudad, queda deslegitimado como óptimo órgano receptor de las impresiones urbanas. A pie de calle, nos rodean infinidad de sonidos, la sensación refrescante de la lluvia, los olores y sus fragancias, las sombras y las luces en movimiento..., incluso muchas anécdotas también visuales, como los colores distintivos de las calles o la mayoría de los elementos que reconocemos cotidianamente en los transcursos diarios, que nunca quedan retratadas en los planos, aunque sean las que le dan ese sabor diferente y característico a la urbe.

Volando con la imaginación. Existe una manera de interpretar la ciudad, que está a caballo entre la abstracción de la realidad y la vivencia misma, que es soñar y proyectar con la imaginación. La imaginación entendida como una pequeña distancia mental, que nos permite estar al mismo tiempo dentro y fuera de las cosas. Una manera más libre de ver la vida, que se apoya en la memoria y la razón a veces, y otras veces, en la sinrazón del

2. "A vista de pájaro" Es una locución adverbial que denota nuestra capacidad de alteridad, a la hora de percibir los objetos, y representarlos "en planta". Para adquirir la extraordinaria agudeza visual de las rapaces en vuelo por los cielos, y salir de nuestro ensimismamiento en la observación de las cosas, introducimos el principio filosófico de la al teridad, que nos ayuda a abandonar las certezas propias, como única vía posible de comprensión, y nos induce a cambiar la perspectiva, completamente por la del otro, para poder percibir el mundo desde su óptica, o sencillamente desde su mismo punto de vista. Algo práctico, para la seguridad del vuelo de las aves, como lo es su certera visión, amplia conceptualmente nuestro marco habitual de percepción y convierte las visiones humanas, otorgándoles un punto de observación elevado, sobre las amplias extensiones del territorio. 
visionario (figura 3). Volando con la imaginación se abren las puertas a otras realidades posibles, llevando a la práctica el imagineering ${ }^{3}$.

Los objetivos concretos del proyecto en sus diferentes enfoques, comprometen a maestros y alumnos, buscando engranar a unos con otros en la planificación urbana y tratando sobre todo de:

- Tomar contacto con la estructura de la ciudad y descifrar sus mecanismos de creación.

- Poner en práctica la capacidad de análisis y observación de la ciudad sobre el terreno, como un requisito previo para revelar la consciencia y la capacidad de una crítica constructiva.

- Preparar a las alumnas y alumnos para la gestión de las crisis, motivadas por el constante cambio y las transformaciones del contexto en el tiempo.

- Abrir espacios para el diálogo mediante prácticas de consenso.

- Apoyar y ofrecer un espacio sorprendente al profesorado interesado en profundizar en explorar nuevas formas educativas, vinculadas a la enseñanza del espacio construido y la ecología urbana, de modo colectivo.

- Aportar nuevas metodologías al aula, información y sistemáticas, como soporte para el desarrollo de muchas de las competencias, como ciencia, tecnología, comunicación lingüística...

- Potenciar el desarrollo de las capacidades del alumnado, a través del estudio del entorno construido y el apoyo de las TIC's, buscando aumentar la capacidad de juicio y el razonamiento lógico, la imaginación, así como, sobre todo, la propia estructuración espacial y vinculación emocional a la ciudad.

El proyecto comprende las siguientes fases:

Preparación y sesiones con el profesorado: En las etapas previas a la puesta en marcha del programa en las aulas, se gesta la motivación del profesorado. Se presta especial atención al maestro, desde la primera convocatoria general, hasta las entrevistas y presentaciones de materiales que tienen lugar de manera individualizada en las aulas, en las que dará lugar la experiencia. Se producen contenidos en formatos accesibles y atractivos en su diseño, para inducir al equipo hacia el trabajo sensible, haciendo virtud del equilibrio entre la forma y el contenido a la hora de crear videos, dosieres, exposiciones, publicaciones... para los maestros que conduzcan la experiencia. Se busca con ellos la manera de interrelacionar las diferentes áreas de conocimiento, para trabajar en combinación con otros maestros. De esta motivación dependerá el buen desarrollo del proceso, que ha introducirse en un momento adecuado del curso escolar, intentando alejarse de las épocas de mayor actividad que se generan en las escuelas en determinadas fechas del calendario escolar. Posteriormente, con la presentación al alumnado y en base

3. Imagineering: dejar volar la imaginación e ingeniárselas para traer de vuelta a tierra lo imaginado. Es un método habitual de trabajo en el planeamiento urbano, que tuvo origen en los años cincuenta en los EEUU. Se materializa mediante prácticas disruptivas y modelos de ideación, con prácticas de tormentas de ideas y demás mecánicas. Este método ayuda a plantear y concretar soluciones desde la imaginación y evidencian la utilidad también de la toma de decisiones rápidas y espontáneas, en determinadas fases creativas de la exploración de la realidad y de su problemática. 
a una planificación realista por etapas, plazos y distribución de tareas, se da comienzo a las metodologías propias del estudio urbano experimental alrededor del centro educativo.

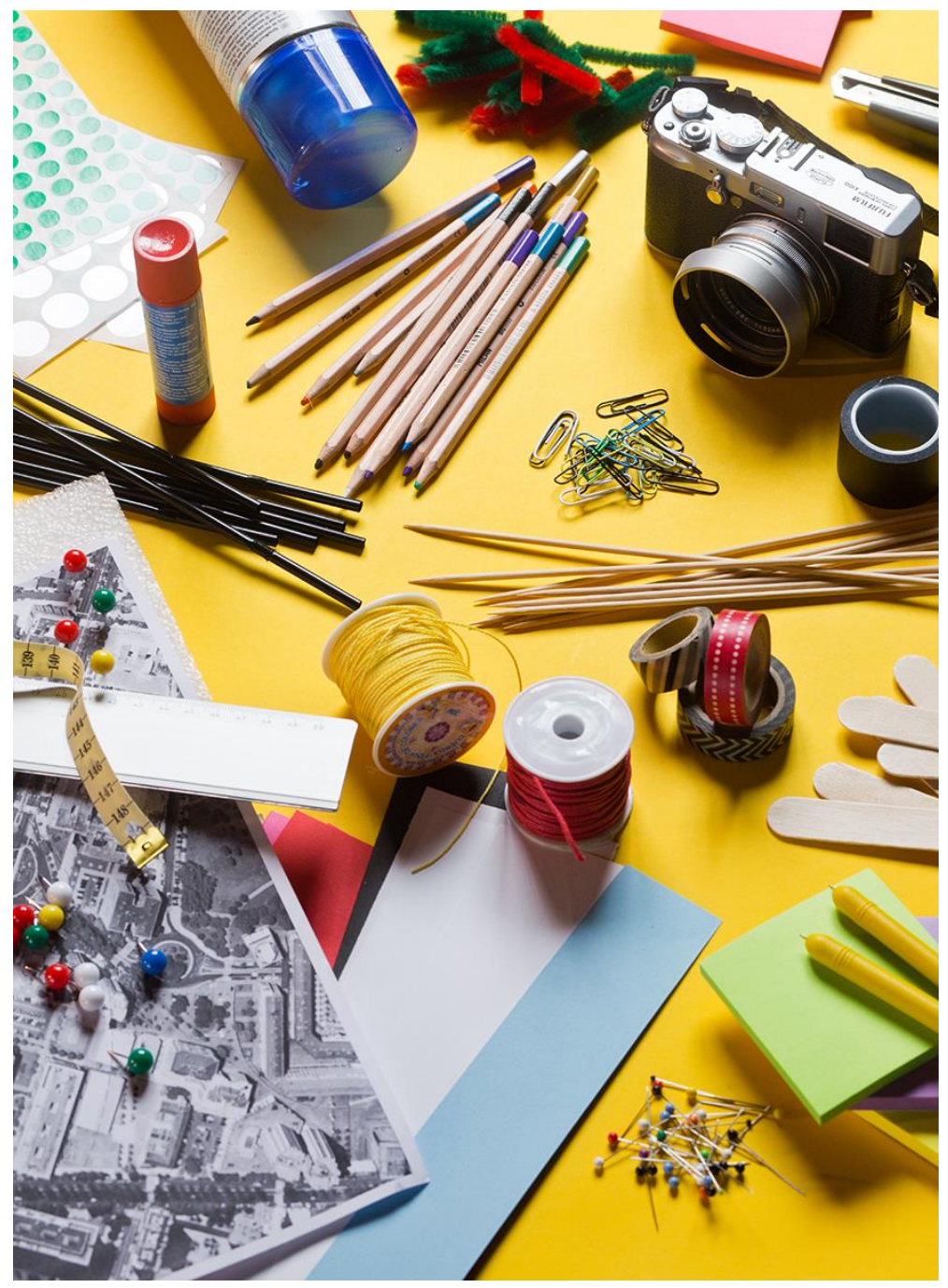

Figura 3. Haurbanistak: Tres maneras de pensar y mirar tu ciudad Fuente: Foto Iñigo Ibáñez 2016.

Recorridos y recopilación de información: Coincidiendo con la primera etapa de observación, detección de problemas, planificación y recopilación de pruebas de la etapa inicial del método MC14, se propone la fase de los recorridos "a pie de calle". Es la etapa de la exploración de la ciudad con todos los sentidos, donde a partir de las salidas del centro escolar, nos encontramos con las nuevas ideas. Para ubicarse dentro del barrio, se hace uso de todos los sentidos y se extienden si es preciso, a base de instrumentos y herramientas: planos, grabadoras de audio, brújulas, cámaras de fotos, lápices y papeles, etc. A partir de amenas caminatas, se observa con atención, se degusta, se olfatea, se palpa y se escucha el ambiente de las calles. Estas informaciones vienen a reflejarse 
después en el aula en mapas sensoriales ${ }^{4}$, a modo de instantáneas multisensoriales del contexto. Resulta de especial interés estar en actitud atenta y sensible al entorno exterior durante los recorridos, puesto que este, de algún modo encierra las preguntas y las respuestas a la vez. Se buscan problemas, aspectos discordantes, inquietantes, espacios que por su singularidad llamen la atención, se sepa o no el porqué. Se fotografían y catalogan. Se deben tomar muestras de todo tipo explorando por "todos los rincones". Es importante aproximarse a la problemática urbana con la mente abierta y sin prejuicios en la búsqueda de las cosas, y ponerse en clave turística en su propia ciudad, observándola con atención. Pero lo más importante, es hacerse buenas preguntas para obtener respuestas correctas. Cuando somos ordenados, realistas y flexibles con nuestros planteamientos, podemos planificar bien nuestros objetivos. Cuando imaginamos introspectivamente con el razonamiento podemos proyectar las soluciones. Se puede completar esta fase de información previa, con la historia del lugar, su toponimia y las anécdotas urbanas en boca de los vecinos del barrio, quienes muchas veces conocen las transformaciones acontecidas hasta llegar al estado actual.

Presentación de los datos recogidos: En esta fase, se trata de la generación de respuestas creativas y alternativas lógicas a las problemáticas detectadas a pie de calle. Se comienza por levantar una sencilla maqueta del contexto urbano en papel, un artefacto para establecer una base de llenos y vacíos, sobre la que continuar analizando a escala, desde el aire, y que pueda servir para proyectar el pensamiento. En esta maqueta, se detecta la forma precisa de calles y plazas. Con sencillos materiales del aula, se trazan las aguas de los ríos o las masas vegetales que contornean la ciudad. Se sitúan esquemáticamente los datos obtenidos en los mapeos de los recorridos realizados por el grupo, así como el camino trazado con sus puntos críticos y de interés que quedarán reseñados en la maqueta.

Formulación de hipótesis: En la sección tercera del método científico, las hipótesis, conjeturas, o suposiciones son, en cierto modo, las soluciones a la definición de los problemas. En esta fase, sobre el contexto de maqueta, se pueden plantear soluciones a problemas o cuestiones que se detectan durante las dinámicas dentro y fuera del aula mediante conjeturas. Las hipótesis de trabajo son necesarias para hacer predicciones de por qué y cómo algo sucederá basándose en su propia conjetura. Son detonantes del pensamiento que sirven de inspiración e inducen al cambio. Podrán orientar los aspectos interesantes a tratar para repensar el barrio. Al formular, son válidas las buenas como las malas hipótesis, ya que estas permiten trabajar por descarte. Es importante recordar que los espacios urbanos cambian, tanto agregando como quitando elementos. Sugiriendo temáticas en el aula basadas en las problemáticas de la ciudad, se anima al grupo a encontrar las ideas candidatas a convertirse en nuestra realidad futura; son las tesis que aspiran a ser probadas, y que para no caer en sus propias paradojas de falta de confirmación, merecen aunque sea a nivel simbólico, ser trasladadas al plano de la realidad y dar pie a cambios. Por pequeña que sea una intervención, el cambio que produce debería ser palpable (Lerner, 2005). En este punto se anima a los estudiantes a predecir las consecuencias del cambio con estos planteamientos, ayudándoles a soñar con diferentes temas: los espacios abiertos en la ciudad, la movilidad y el transporte urbano,

4. Los mapas sensoriales son mapas alternativos para la interpretación de un lugar. Se obtienen a partir de caminatas o paseos colaborativos, para recabar la información y su posterior puesta en común en un plano bidimensional de ese espacio. La toma de datos sucede generalmente a partir de los cinco sentidos sin priorizar la vista. 
la alimentación, la energía o la sostenibilidad futuras, así como la vivienda actual, la educación, la cultura o la convivencia ciudadana.

Propuestas y debate: Es el momento de incorporar los ingredientes de apoyo y los métodos creativos, los lógicos y los no tan lógicos. Se formulan individualmente los deseos para el barrio antes de pasar al debate en grupo. El modo de avanzar en esta fase es progresiva en complejidad, comenzando desde la formulación en un sencillo post $i t$, del que se salta al plano del dibujo donde los estudiantes tienen pueden expresar amplificadamente los conceptos, (hemos podido observar que el dibujo es una herramienta de expresión cómoda para la infancia, que muestra aspectos que sus palabras no desvelan). A la hora de plantear las hipótesis simbólicamente sobre el terreno de la maqueta, es probable que coincidan varias propuestas para incidir en el mismo lugar. La práctica democrática de debatir las ideas, en esta fase previa a las conclusiones, hace fuerte a las ideas y a las personas. El respeto a las propuestas de los demás, la capacidad de juicio propio y la atenta escucha, garantizarán el debate. No todas tendrán las mismas características. Las propuestas más deseables suelen ser las que suman conocimiento a la hora de responder a un problema concreto, las más sencillas, o las que más verosimilitud o capacidad de producir consecuencias tienen.

Exposición y evaluación: Por fin, se llega al momento final de la evaluación y sus conclusiones. Con la concreción de las ideas finales en la maqueta, de manera sencilla finaliza la propuesta, de la que sin duda derivan infinidad de buenas ideas urbanas, en todo tipo de formato: planos, fotografías, dibujos... con todo este material en forma de propuesta plástica, se está en disposición de pasar las conclusiones y reflexiones, a una exposición en el centro escolar, para la puesta en valor de las soluciones nacidas desde la participación democrática, activa y crítica (figura 4).

Tras la experiencia de estos años, con el proyecto Haurbanistak, hemos podido escuchar algunas de las necesidades que los participantes detectan en su entorno urbano. Lo mismo trabajando mediante sistemas en base a ensayo y error, como trabajando mediante planteamientos más reflexivos, las niñas y niños, esperanzan nuestro futuro con propuestas urbanas lógicamente posibles, consistentes con lo mejor de la ciudad que reciben y tratando de producir beneficio consecuentemente a sus planteamientos de ciudad, desde el presente, pero con cierta perspectiva de futuro. De llevarse a la práctica sus ideas, "La ciudad de los niños de San Sebastián", sería más jugable y divertida que la actual, siendo una representación para todos los públicos, incluidos los animales. Siendo como es su concepto de justicia, mucho más rebelde contra la injusticia, nos alejan de la peligrosidad con sus inventos a la que nos arrojan nuestros vicios sociales induciéndonos al agravio y a qué a lo que no es justo.

Para solventar la incertidumbre que les plantea su contexto inmediato y futuro, responden hoy con altruismo y generosidad. Los niños piensan en todas las edades del hombre sin excepción, empatizando de antemano con todos los estados que ha de vivir a lo largo de su existencia. En ese estado de crecimiento continuo que les caracteriza, se imaginan a sí mismos de jóvenes, adultos y ancianos, permitiéndoles una alteridad imprescindible para la construcción moral de esa solidaridad entre las personas que forman una sociedad sensible. Los estudiantes en general, optan por decisiones de diseño muy sencillas, soluciones muy lógicas y a la vez muy radicales en su concepción. A continuación, remitiéndonos a los resultados de las tres exposiciones colectivas que se realizaron entre todos los centros participantes, y por temáticas, podemos apreciar qué 
tipos de problemáticas encuentran las niñas y niños en la ciudad, y qué posibles soluciones nos ofrecen para la ciudad de San Sebastián.

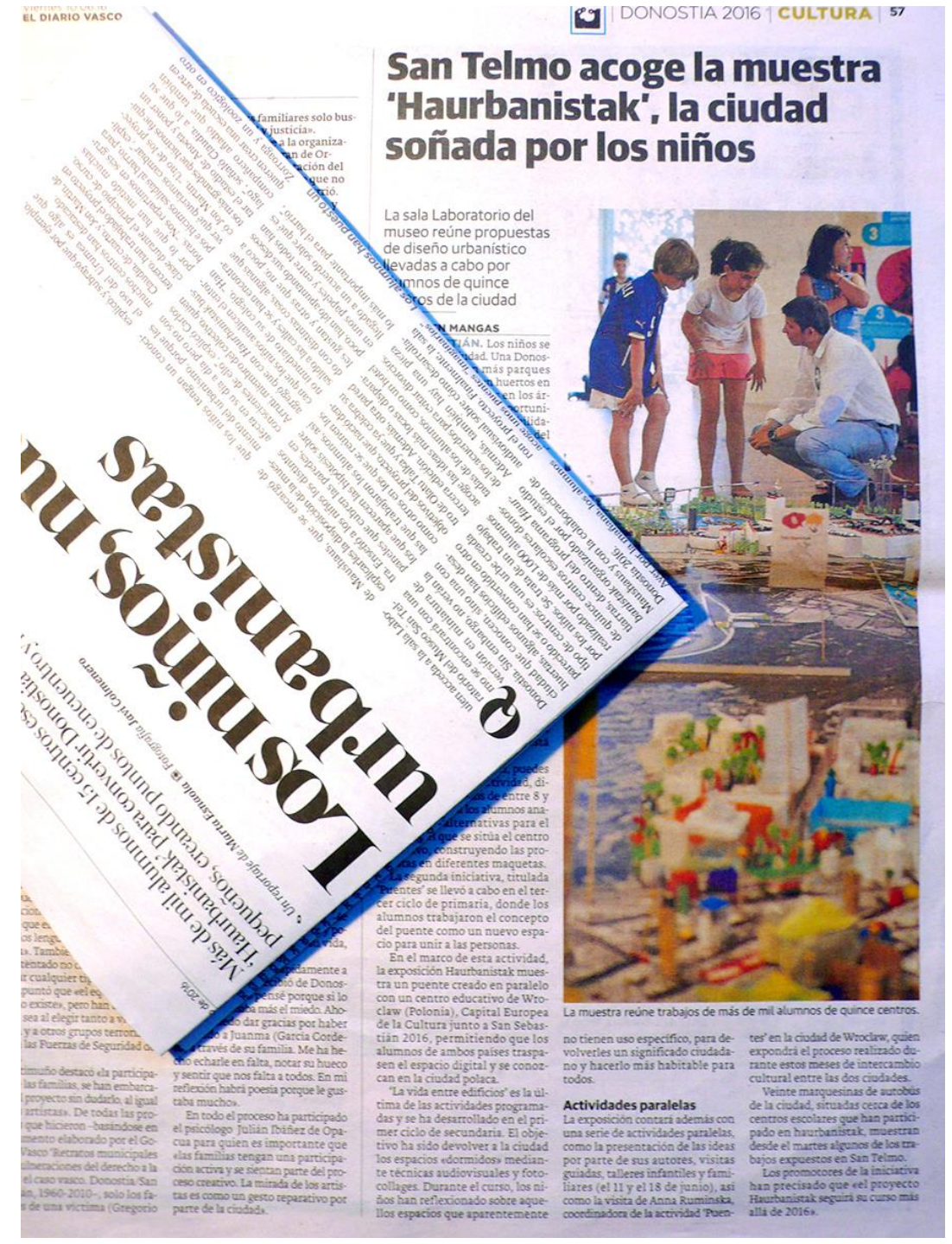

Figura 4. Artículos en prensa exposición Haurbanistak en junio 2016

Fuente: Foto Maushaus 2016.

Movilidad y transporte: Separan el tráfico rodado de sus caminos para poder disfrutar de la ciudad de una manera más segura y libre. En las zonas con grandes desniveles topográficos buscan soluciones de movilidad, recurriendo a soluciones creativas pensando en todos los ciudadanos en su rango de edad, evitando el uso del coche y pensando en vehículos alternativos a ese modelo que descartan: bicicletas eléctricas, funiculares, tranvías, tirolinas, toboganes, sistemas teleféricos o tele-transportadores de materia.

Ellos encuentran que al expulsar el coche de la ciudad, evitan la contaminación que produce el vehículo de gasolina, a la vez que consiguen apoderarse de vastas superficies de terreno para disponer de nuevos usos (carriles de bicicletas para articular la movilidad urbana, más zonas peatonales, grandes espacios verdes o de cultivo). Buscan también, en la propia naturaleza esas nuevas vías: revalorizan el río convirtiéndolo en un parque 
fluvial dónde tiene cabida todo tipo de deportes. El río deja de ser una barrera entre dos vegas, y pasa a ser un elemento vertebrador. A escala más pequeña, sin intentar solucionar el problema global del transporte, detectan desajustes y conflictos entre peatón y vehículo, como los desproporcionados tiempos de los semáforos, o la falta de pasos de cebra en determinados lugares de la ciudad.

Espacios abiertos en la ciudad: Quieren jugar y que la ciudad sea más jugable a la vez que proponen una ciudad para todas y todos. Expresan que los espacios de juego, diseñados para ellos, son estáticos e inalterables y reclaman el poder diseñar o transformar a su gusto estas áreas. Proponen acciones lógicas en los espacios abiertos, como la realización de picnics en los parques, proyección de cine al aire libre y múltiples actividades al aire libre, como talleres, deportes o conciertos... Reclaman pequeños ajustes prácticos como la instalación de fuentes y aseos públicos en puntos concretos de su entorno.

Alimentación y naturaleza: Desean más naturaleza en la ciudad (árboles frutales, vegetación para el disfrute visual, huertas para alimentarnos más sanamente...). Proponen ferias de producto local y la convivencia con los animales, como si la ciudad fuese una gran granja, como una mezcla de las prácticas rurales y urbanas. Curiosamente su mirada, no sólo se queda en el plano de la ciudad, sino que mira al cielo, buscando en lo que esconde el cielo, plantean observatorios astronómicos o lugares para la observación de las estrellas.

Energía y sostenibilidad: Los escolares plantean energías limpias y su captación mediante placas solares, molinos de viento, transportes con energías renovables, sistemas magnéticos..., que trastocan las visiones de las rojas y negras visiones de nuestros tejados, por verdes cubiertas donde cultivar y cosechar.

Vivienda: Siendo el hogar el refugio seguro de la infancia, son conscientes de lo que supone la falta de vivienda. Son muy sensibles a las situaciones que implican a las personas con la carencia de un techo. Por ello, proponen nuevas construcciones, o la reutilización de edificios en desuso, para acoger a personas desplazadas por diferentes conflictos socio-políticos. En su modelo de ciudad, nadie queda sin hogar.

Educación y cultura: El concepto artístico asociado a la inmediatez de la expresión y no tanto a atesorar valores artísticos, tiene reflejo en deseos como el Museo de los Niños. Un lugar más asociado a la creación que a la conservación. Las niñas y niños proponen un museo donde la obra cambia permanentemente y es imposible acudir al estado anterior. Proponen también la ciudad como lienzo y escuela, utilizando las fachadas de los edificios como soporte gráfico, con mensajes para los ciudadanos.

Convivencia: Dada la agilidad con la que acostumbran a mediar los conflictos internos con dinámicas de acuerdo en el aula, los niños se sorprenden de nuestra falta de recursos a la hora de establecer estrategias para solventar las desavenencias entre los adultos, que tantas veces acaban deshabilitando su mundo con cambios de domicilio, de referentes familiares o de centros escolares, que amenazan la seguridad de su mundo. Como anécdota plausible, nos plantean el Hotel de los Acuerdos, un lugar que descarga de las tareas domésticas a los familiares, y les permite resolver mediante el diálogo sus diferencias (figura 5). 


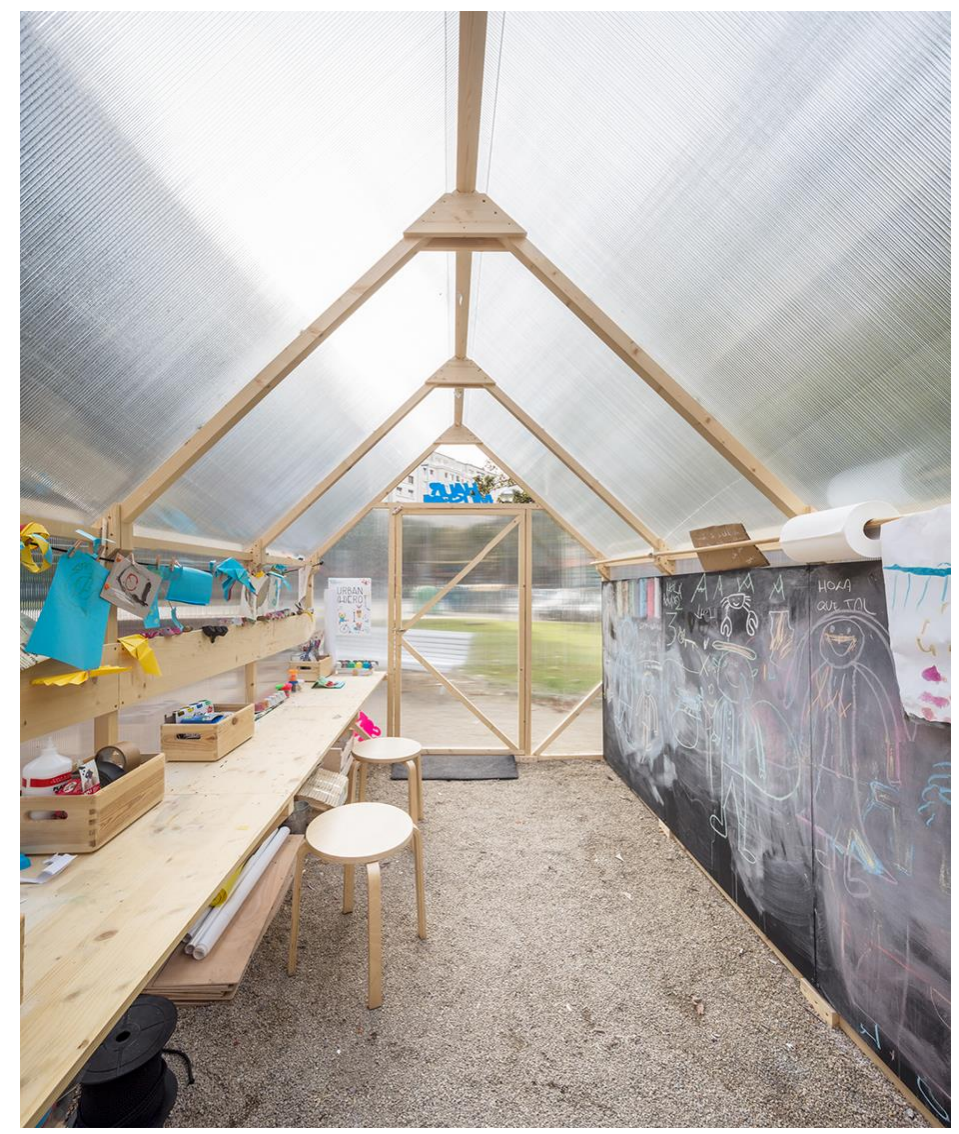

Figura 5. Intervención urbana del Museo de los Niños Fuente: Foto Jon Arruti 2016.

El proceso descrito y los resultados con los que finaliza el proyecto, pretenden afianzar la capacidad crítica del alumnado en el sentido estricto de proporcionarles criterio. Criterio ante la vida y sus cambios permanentes. Tal y como mostramos en los primeros objetivos, la pretensión final de todas estas metodologías no es la de crear urbanistas, si no, la de devolver la urbanidad a la ciudad mediante el mundo de las ideas.

A modo de autocrítica constructiva, podemos ahora encontrarnos con aspectos a mejorar en futuras experiencias:

- Es importante salir de la zona de confort del aula, para sacar las ideas a la calle (con una acción o performance urbana) para poder comprobar su trascendencia y validez de la hipótesis en su contexto real.

- Dedicar un tiempo al proceso de evaluación interno en aula. Es decir, una vez el grupo de alumnos han consensuado una solución o mejora a un aspecto urbano, y realizado ese cambio, evaluar si realmente ese cambio es positivo para todos los ciudadanos. En relación a esta idea, podemos aprender mucho de la experiencia alemana del colectivo "Jas 5 ", ya que la legislación alemana, integra la participación infantil y juvenil dentro de su marco de ley.

5. Entrevista realizada por Andrés Morales Zambra, Ciudadanía y Territorio - Departamento de Geografía, Universidad Alberto Hurtado, Chile, a Päivi Kataikko, encargada de asuntos regionales e internacionales del colectivo Jugend 
- La calidad de los resultados es directamente proporcional a la motivación del maestro. Es importante alimentar la motivación del profesorado con viva comunicación, tanto al principio del proyecto, como durante todo el desarrollo del programa en las aulas.

- A veces se puede llegar a contaminar la experiencia de la prueba con sólo mostrar a los estudiantes los resultados de experimentos de años anteriores, que nublan el juicio de algunas propuestas e invalidan el resultado objetivo del resultado.

- Podemos asegurar una recogida de los materiales producidos por los escolares, mediante protocolos de comunicación en la entrega final, que aseguren que toda la información recibe el tratamiento correcto de documentación y filtrado, que permita la transmisión de todas sus ideas, sin perdernos detalles e ideas por el camino.

- Siempre podemos mejorar la comunicación visual de nuestros materiales base para los proyectos: videos, dosieres... en el momento de inducir a un grupo a crear ideas propias, conviene sugerir antes que evidenciar.

- Al ser un proyecto en el que se plantea el estudio del barrio circundante al centro educativo, hemos podido ver que el propio centro no es objeto de análisis, habiéndose dado la opción de estudiar el patio del mismo como espacio exterior abierto en la ciudad.

- Se deben repetir abundantemente este tipo de experiencias, hasta normalizar el hecho participativo infantil en nuestra sociedad, ajustando los contenidos cubriendo al mayor espectro posible de edades, y generando y mejorando, nuevas experiencias de comunicación, hasta elevarles a un plano político, por qué no.

Reivindicamos la introducción de procesos y prácticas artístico-técnicas entre los objetivos de la enseñanza en las escuelas, como garantía para provocar nuevas ideas, y por su naturalidad a la hora de involucrar la participación de las personas en los procesos de aprendizaje y de cambiar su percepción del mundo, a pesar de toda la confrontación y contradicción que ello provoca. Las escuelas necesitan más creatividad para afrontar un futuro innovador. Los objetivos de la educación para el desarrollo ético de la infancia, son compatibles con la aproximación que permite la pedagogía urbana. Las incompetencias educativas merecen una segunda lectura.

Creemos en la necesidad de una revolución cultural, para no convertirnos en consumidores pasivos de situaciones y productos diseñados por especialistas. Valoramos un futuro próximo en el que niñas y niños puedan participar del diseño de nuestras ciudades. Entendemos que produciendo modelos urbanísticos más flexibles, los usuarios encontraremos en los márgenes de esa indefinición, el lugar decisivo que nos corresponde para definir con nuestros usos los nuevos programas de la ciudad. Vemos a las escuelas como contexto ideal para la adquisición de los valores democráticos, que anteponen a diario los intereses del grupo sobre los particulares, en un ejercicio sano de su ideario de justicia. Estamos tranquilos entregando las llaves de la ciudad a los niños. 


\section{Referencias}

Aristóteles. (1918). Ética a Nicómaco. Pedro Simón Abril (Trad.). Albacete: Servicio de publicaciones de la diputación de Albacete.

Lamarck, J. B. (1971). Filosofía zoológica. Barcelona: Editorial Mateu.

Lerner, J. (2005). Acupultura urbana. Barcelona: IaaC.

Nielsen, P. (2010). El model. Un model per una sociedat cualitativa. Barcelona: MACBA.

Platón. (2010). Apología de Sócrates. Enrique López Castellón (Trad.). Madrid: Austral.

Tucídides. (2004). Historia de la guerra del Peloponeso. Francisco Romero Cruz (Trad.). Madrid: Cátedra.

\section{Breve CV de los autores}

\section{Carlos Arruti Echeverria}

Realizó sus estudios en la E.T.S.A. de Navarra y en la E.T.S.A. de San Sebastián. Cofundador del estudio de arquitectura Rulot en el 2001, crea junto con Anabel Varona, en el año 2009, el proyecto de educación de arte y arquitectura para niñas/os Maushaus. Dentro de este marco, ha redactado diversas comunicaciones y ponencias como la presentada en el VIII Congreso DOCOMOMO Ibérico celebrado en Málaga, La arquitectura del Movimiento Moderno y la educación, "La arquitectura como experiencia colectiva: estrategias de juego y aprendizaje estético en la infancia”. Desde el año 2012, forma parte del equipo editor de la Revista de Arquitectura para niños Amag! En el año 2016, ha publicado el libro "La Arquitectura a través del juego" editado por la Fundación Arquia y Los Libros de la Catarata, así como el recurso educativo "1,2,3 Haurbanistak, tres formas de mirar y pensar tu ciudad” editado por la Oficina de la Capitalidad Cultural Donostia /San Sebastián 2016. ORCID ID: 0000-0003-1372-6102. Email: carlos@maushaus.info

\section{Anabel Varona Martínez}

Arquitecta por la E.T.S.A. de San Sebastián. Co-fundadora del estudio de arquitectura Rulot en el 2001, crea junto con Carlos Arruti, en el año 2009, el proyecto de educación de arte y arquitectura para niñas/os Maushaus. Dentro de este marco, ha colaborado en el diseño de espacios destinados a la infancia y al aprendizaje lúdico, así como en procesos y dinámicas participativas. En enero de 2012, junto con Jorge Raedó y diferentes colaboradores internacionales, publica el primer artículo de la Revista de Arquitectura para niños Amag!, formando parte desde entonces del equipo editor. Compagina la docencia artística y arquitectónica, con la creación de programas y contenidos educativos para el profesorado en centros de educación infantil, primaria y secundaria. Es co-autora de comunicaciones, ponencias y publicaciones sobre educación de arquitectura para la infancia como "La arquitectura a través del juego" y "1,2,3". ORCID ID: 0000-0001-6202-1534. Email: info@maushaus.info 